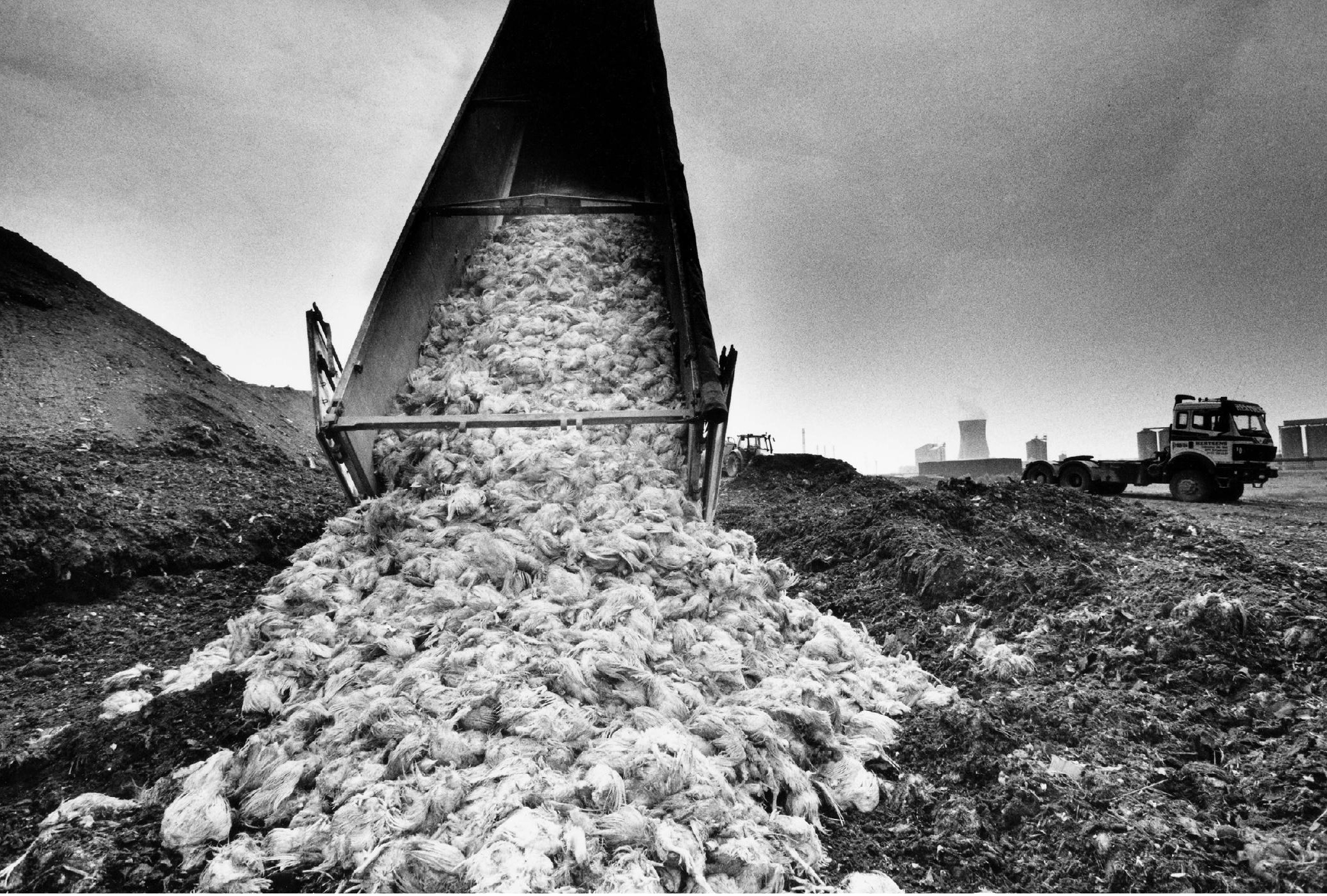

Contaminated chickens are offloaded in a landfill site in Belgium in 1999.

\title{
SUSTAINABILITY
}

\section{Globe to gut: inside Big Food}

Felicity Lawrence absorbs three books on the illogical route from farm to fork.

$\mathrm{E}$ very year, roughly one-third of food produced for human consumption goes to waste. The booming global livestock population accounts for $15 \%$ of human-caused greenhouse-gas emissions. Its more than 20 billion chickens, 770 million pigs and 1.5 billion cattle eat around one-third of all cereals produced. More than 390,000 tonnes of asparagus are flown to rich countries from regions of Peru experiencing acute water shortages and extreme poverty. Some 820 million people go hungry. More than 650 million adults are obese.

That our current food system is not fit for purpose is now a widely accepted diagnosis. The symptoms are severe. In addition to its implications in climate change and water scarcity, Big Food is a factor in crises of soil depletion, biodiversity loss and pollution. The aetiology of the disease remains disputed, however; so, as three new books demonstrate, the proposed remedies differ wildly.

Robyn Metcalfe's Food Routes argues for
Food Routes: Growing Bananas in Iceland and Other Tales from the Logistics of Eating MIT Press (2019)

The Grand Food Bargain: and the Mindless Drive for More

Island (2019)

Eating Tomorrow: Agribusiness, Family

Farmers, and the Battle for the Future of Food

The New Press (2019)

total reinvention through technology: with big data's marriage to Big Food, technology companies and engineers will soon take over from farmers to produce what we eat. In The Grand Food Bargain, Kevin Walker counters that view, warning of our tendency to overestimate short-term benefits of new technology, and to underestimate any damaging consequences. And in Eating Tomorrow, Timothy Wise writes a powerful polemic against agricultural technology that is sold to developing countries as progress towards the common good, but that ends up as a tool of agribusiness oligopoly and profit.

Metcalfe, a food futurist, declares herself a technology optimist. Food Routes is a fascinating catalogue of 'miracle' solutions in development. Some $-3 \mathrm{D}$ printed pizzas, say - are from the wilder shores of businessschool horizon scanning. Others, such as gene editing of seeds, are about to be embedded in our lives, yet we're mostly oblivious to their unforeseen consequences.

Metcalfe predicts that new technologies will affect every part of the food chain, from seeds and agricultural chemicals to how food is moved - starting in a post-soil field, lab or vertical factory, zipping through logistics hubs full of driverless vehicles and networked machines, and delivered by drones. She revels in how smart farm machinery can collect vast quantities of data on soil status and crop characteristics, and in how it can integrate 
those with satellite navigation, weather data and irrigation systems to allow for precision application of pesticides, fertilizers and water.

The Green Revolution of the 1950s and 1960s vastly boosted global food output using new, high-yielding crop varieties, synthetic fertilizers, pesticides and fossil-fuel energy. But it has another legacy: environmental crises from pest resistance to the derailing of the nitrogen and phosphorus cycles. Ironically, the new miracles promised in this book are designed to address some of the unforeseen consequences of these old ones. Metcalfe does not let that dampen her enthusiasm.

Past debates over genetic modification (GM) centred on issues such as whether it was safe to insert DNA from other organisms, such as soil bacteria, into crops including maize (corn), or whether GM was just a way of selling more pesticide. Discussions are now turning to CRISPR technologies, which enable scientists to edit DNA sequences within organisms. The technique promises nutritionally enhanced eggs, bread without gluten, and pest-resistant wheat. It could even deliver smaller, slower-growing chickens - although that could be done by simply returning to oldfashioned breeds, now superseded by overbred poultry varieties from dominant supply companies Cobb Vantress and Aviagen.

On the retail-to-consumer end, Metcalfe explains how data will be tracked using sensors and blockchain databases that contain time-stamped logs with unique fingerprints of every transaction. That will reveal the provenance of every kidney bean or drop of milk (as long as no one in the chain submits fake data). Companies that sell us food will use personal health records and artificial intelligence to create personalized meals approved by insurance companies and employers, including lab-produced proteins.

Precision agriculture ought to be good news for farmers. Equipment manufacturers, however, consider themselves the owners of data collected by a farmer using their machinery. Along with these data, power and money will flow away from farmers at the bottom of the chain to big companies at its top, as they have with seed technology. Meanwhile, US regulators have given gene editing the green light with little testing because it does not introduce foreign DNA; the European Union, by contrast, has ruled that CRISPR used for agriculture must be strictly regulated. On all these ethical issues, and the crucial issue of data and privacy, Metcalfe is breezily insouciant, "deferring social and political change for another discussion". In her wildly optimistic future, all is for the best in the best of all possible business-centric worlds.

Walker's The Grand Food Bargain provides an antidote: a thoughtful analysis of how the food system got into this mess. He is no Luddite, having worked in both agribusiness and the US Department of Agriculture on technical fixes. $\mathrm{He}$ was present at early conversations about GM that began, he

\section{"We have created asystem that mindlessly pushes for quantity and mostly ignores quality and environmental impacts."}

says, with agrochemical producers looking for ways to keep pushing their products after pesticide patents expired. Raised amid the hard graft and repeated losses of a Utah farm, he has also worked in developing countries. His perspective is sensitive to wider contexts.

Walker thinks that an unspoken deal is the heart of the food problem. We have created a system that mindlessly pushes for quantity and mostly ignores quality and environmental impacts. Consumers get cheap, plentiful food; industry gets bigger profits from selling

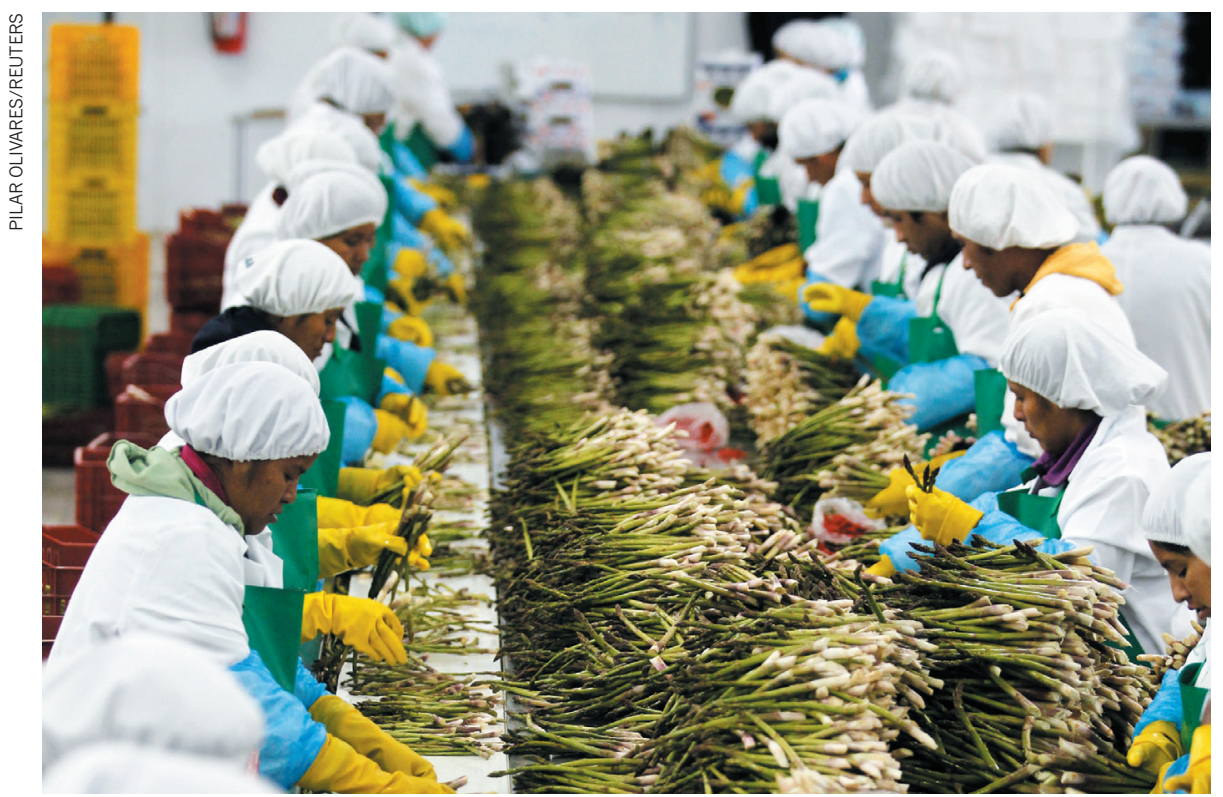

Workers sort asparagus for export in Ica, Peru. more. The US government, for example, subsidizes that surplus by using taxpayers' money on successive Farm Bills: the latest in these multiyear settlements, agreed in 2018, was for almost US $\$ 900$ billion. They have mainly bolstered maize, wheat, soya and rice, as well as cotton. But this plenty is misused. The first three crops make their way into the vast majority of processed foods globally. They are refined into starches and sugars and combined with additives to create variety where it has been eliminated, or are fed to farmed animals. It's a long way from our evolutionary past, when food was scarcer and our ancestors expended significant energy in finding it.

Walker reveals a disturbing political, social and economic landscape. Here are the concentrations of corporate power in most commodities and processing, agribusiness's buying of political influence, the privatization of profit through intellectual-property law, and the inability of the market economy to account for the true cost of farming. This is also the territory that Wise - a researcher in land and food rights - explores in Eating Tomorrow. In low-income countries, he argues, foreign agribusiness has hijacked the agenda by promoting patented seeds for commodity monocrops and expensive synthetic fertilizer as the answer to feeding the poor. As is clear from his research, from Malawi to Mexico, agribusiness and local elites capture the wealth while leaving local people to pick up the environmental tab.

Walker, too, is strong on environmental impacts: monocrops (such as the Cavendish banana) vulnerable to extinction as a result of disease; pesticide-resistant superweeds, such as Palmer amaranth (Amaranthus palmeri); antibiotic resistance from intense livestock farming; pollution from agrochemicals. The drive for more, he shows, demands profligate use of finite resources, from energy to land. US soil, for instance, is depleted 18 times faster than nature can rebuild it.

His diagnosis has been articulated before, by environmental and agroecology thinkers such as Raj Patel, Tim Lang and George Monbiot. But Walker's experience in agribusiness adds authority. At a vast US farm cooperative in his early career, he had to work out how to sell more fertilizer. He mathematically modelled how more inputs could increase yields and sales. Yet some versions of the model showed a tipping point: returns went down, and runoff to waterways caused loss.

Walker left with the bubbling anxiety that our focus on technological and scientific fixes blinkers us to the environmental cost of our greed. Ignore the irrevocable laws of nature for long enough and we put our own, rather narrow, ecological niche at risk.

Felicity Lawrence is special correspondent for The Guardian in London and author of Not on the Label and Eat Your Heart Out. e-mail:felicity.lawrence@theguardian.com 